\title{
A Combined Metabonomic and Proteomic Approach Identifies Frontal Cortex Changes in a Chronic Phencyclidine Rat Model in Relation to Human Schizophrenia Brain Pathology
}

\author{
Hendrik Wesseling', Man K Chan', TM Tsang ${ }^{2}$, Agnes Ernst', Fabian Peters', Paul C Guest', Elaine Holmes ${ }^{2}$ \\ and Sabine Bahn*, 1,3 \\ 'Department of Chemical Engineering and Biotechnology, University of Cambridge, Cambridge, UK; ${ }^{2}$ Department of Biomolecular Medicine, \\ Faculty of Medicine, Imperial College, London, UK; ${ }^{3}$ Department of Neuroscience, Erasmus Medical Center, Rotterdam, The Netherlands
}

\begin{abstract}
Current schizophrenia (SCZ) treatments fail to treat the broad range of manifestations associated with this devastating disorder. Thus, new translational models that reproduce the core pathological features are urgently needed to facilitate novel drug discovery efforts. Here, we report findings from the first comprehensive label-free liquid-mass spectrometry proteomic- and proton nuclear magnetic resonance-based metabonomic profiling of the rat frontal cortex after chronic phencyclidine (PCP) intervention, which induces SCZ-like symptoms. The findings were compared with results from a proteomic profiling of post-mortem prefrontal cortex from SCZ patients and with relevant findings in the literature. Through this approach, we identified proteomic alterations in glutamate-mediated $\mathrm{Ca}^{2+}$ signaling $\left(\mathrm{Ca}^{2+}\right.$ /calmodulin-dependent protein kinase II, PPP3CA, and VISLI), mitochondrial function (GOT2 and PKLR), and cytoskeletal remodeling (ARP3). Metabonomic profiling revealed changes in the levels of glutamate, glutamine, glycine, pyruvate, and the Ca ${ }^{2+}$ regulator taurine. Effects on similar pathways were also identified in the prefrontal cortex tissue from human SCZ subjects. The discovery of similar but not identical proteomic and metabonomic alterations in the chronic PCP rat model and human brain indicates that this model recapitulates only some of the molecular alterations of the disease. This knowledge may be helpful in understanding mechanisms underlying psychosis, which, in turn, can facilitate improved therapy and drug discovery for SCZ and other psychiatric diseases. Most importantly, these molecular findings suggest that the combined use of multiple models may be required for more effective translation to studies of human SCZ.

Neuropsychopharmacology (20I3) 38, 2532-2544; doi:I0.1038/npp.20 I3.160; published online I4 August 20I3
\end{abstract}

Keywords: chronic phencyclidine rat model; schizophrenia; post-mortem brain; LC-MS'; 'H-NMR; calcium signaling

\section{INTRODUCTION}

Schizophrenia (SCZ) is a chronic mental disorder that affects up to $1 \%$ of the population worldwide. It is widely accepted that it is not a single disease entity, but represents the symptomatic manifestations of diverse etiologies. The underlying causes are still not fully understood, resulting in only partial success with early diagnosis and no novel drug entities discovered over the past decade. The latter effect results from the lack of preclinical models, which accurately reflect the underlying pathologies (Sarnyai et al, 2011). In particular, modeling SCZ in animals is made difficult by the poor translation of behavioral readouts to the diverse, nonspecific symptoms of the human disease. This may also be because of the fact that such behavioral measures

*Correspondence: Professor S Bahn, Department of Chemical Engineering and Biotechnology, University of Cambridge, Tennis Court Road, Cambridge, Cambridgeshire CB2 IQT, UK, Tel: + 441223 334 I5I, Fax: + 44 I223 334 |62, E-mail: sb209@cam.ac.uk

Received 6 February 2013; revised 3 June 2013; accepted 14 June 2013; accepted article preview online 3 July 2013 are subjective and they do not strictly correspond to the actual symptoms in humans. Successful translational research requires animal models that can recapitulate disease-associated mechanisms at the molecular level and thereby model the disease in an empirical manner. Ideally, behavioral and molecular signals should be modeled in parallel.

The most frequently used models for SCZ research and drug discovery include those involving phencyclidine (PCP) treatment of rodents. PCP treatment of rodents over both acute (Ernst et al, 2012; Neill et al, 2010) and chronic (Hashimoto et al, 2005; Marquis et al, 2003; Murai et al, 2007; Qiao et al, 2001) intervals is thought to induce a psychosis-like state through blockade of $N$-methyl-Daspartate (NMDA) receptor activity, which results in altered levels of glutamate and increased dopamine. Alterations in glutamatergic and dopaminergic neuronal transmission in the stratium and frontal cortex have been implicated in the etiology of human SCZ, and the model was derived from observations of acute psychotomimetic effects of PCP in healthy humans and exacerbation of symptoms in chronic 
SCZ patients (Lahti et al, 1995; Mouri et al, 2007a). In rodents, enduring behavioral abnormalities similar to those seen in SCZ have been noted after chronic PCP (cPCP) administration, including hyperactivity, decreased social interaction, decreased motivation, and impaired cognitive function (Hashimoto et al, 2005; Marquis et al, 2003; Murai et al, 2007; Qiao et al, 2001). At the neuroanatomical level, altered prefrontal dendritic spine density (Hajszan et al, 2006) and shrunken neuronal morphology (Ellison and Switzer, 1993) have also been observed, reflecting aspects of the etiology of human SCZ (Keshavan et al, 2008). Therefore, a better understanding of these central nervous system effects at the molecular level would have the potential to increase the utility of this model for drug discovery through the identification of companion biomarkers and novel targets.

With this objective, we have carried out the first systematic investigation of the molecular changes, which occur in the frontal cortex of the cPCP rat model using a combination of proteomic and metabonomic profiling approaches. Our primary objective was to determine how many of these molecular changes were also evident in post-mortem frontal cortex tissue from SCZ patients to evaluate the translational validity of the model.

\section{MATERIALS AND METHODS}

\section{Animal Handling and Treatment}

Adult male Sprague-Dawley rats (200-300 g; Charles River, Margate, UK) were housed in groups of four under standard laboratory conditions with food (Harlan UK, Bicester, UK) and water available ad libitum. All experiments were conducted during the light cycle and were in full compliance with the Home Office Guidance (UK Animals Scientific Procedures Act 1986) and ethical policies of the Home Office. After a 10-day adaptation period, rats were given a daily subcutaneous dose of vehicle $(0.9 \%$ sterile saline) or PCP $\mathrm{HCl}(5 \mathrm{mg} / \mathrm{ml})$ for 15 consecutive days. All animals were killed by decapitation $2 \mathrm{~h}$ after the last injection and frontal cortices were dissected on ice and frozen immediately in liquid nitrogen, as described previously (Ma et al, 2009).

\section{Behavioral Experiments}

To assess locomotor activity and stereotypy, saline- and PCP-treated rats were placed into an IR Actimeter System (Panlab, Barcelona, Spain) after the last injection (day 15). The rats were given a 1-min habituation period before locomotion and stereotypy recordings were performed. These assessments were taken every $10 \mathrm{~min}$ post injection for $90 \mathrm{~min}$. Locomotion was recorded using an automated locomotion activity chamber (Ernst et al, 2012) and stereotypy was rated based on the scale of (Sturgeon et al, 1979).

\section{Human Post-Mortem Brain Samples}

Post-mortem dorsolateral prefrontal cortex (DLPFC; Brodmann area $9, n=20$ ) samples were obtained from the
Stanley Medical Research Institute (Bethesda, MD). The average fluphenazine mg equivalent was used as an indicator of cumulative lifetime antipsychotic dose and this showed that the patients had received an average low medication rate (Supplementary Table 1). No significant differences were found in secondary axis diagnosis of alcohol abuse/dependency and drug abuse/dependency between patients and controls (Fisher's exact test). Also, the sample groups were matched for post-mortem interval, brain $\mathrm{pH}$, age of death, and gender. Tissues were sectioned (approximately $70 \mathrm{mg}, 15 \mu \mathrm{m}$ slices) using a Leica Cryostat (Milton Keynes, UK), collected into prechilled lysing matrix D tubes (MP Biomedicals, Cambridge, UK) and stored at $-80{ }^{\circ} \mathrm{C}$ until use.

\section{Metabonomics}

${ }^{1} \mathrm{H}$-nuclear magnetic resonance spectroscopy profiling. Rat frontal cortex tissues (30 mg) were homogenized in $1 \mathrm{ml}$ acetonitrile:deionized water $(1: 1)$, as described in Chan et al (2011) and centrifuged at $4800 \mathrm{~g}$ for $10 \mathrm{~min}$ after $0.5 \mathrm{ml}$ $3: 1 \quad(\mathrm{v} / \mathrm{v})$ chloroform/deuterated-methanol was added. The aqueous phases was collected and dried overnight, for complete evaporation of acetronitrile, and freeze dried at $70^{\circ} \mathrm{C}$. Samples were reconstituted in $700 \mu$ of deuterium oxide $\left(\mathrm{D}_{2} \mathrm{O}\right)$ containing $1 \mathrm{mM}$ trimethylsilyl propanoate (TSP). $\mathrm{D}_{2} \mathrm{O}$ provides a deuterium field frequency lock for the nuclear magnetic resonance (NMR) spectrometer, whereas TSP provides an internal chemical shift. All extractions were performed under blind and randomized conditions.

Rat tissue extracts were transferred into $5-\mathrm{mm}$ diameter NMR tubes and loaded onto a Bruker AV600 spectrometer (Bruker Avance, Bruker GmBH, Rheinstetten, Germany) and spectrally acquired using the first increment of the Nuclear Overhauser Enhancement Spectroscopy (NOESY) pulse sequence $\left(\mathrm{RD}, \pi / 2-t_{1}-\pi / 2-t_{\mathrm{m}}-\pi / 2-\mathrm{Acq}\right.$; $\left.\mathrm{TR}=3 \mathrm{~s}\right)$ as described previously (Chan et al, 2011; Lan et al, 2009). Chemometric modeling of ${ }^{1} \mathrm{H}-\mathrm{NMR}$ data was performed as described (Chan et al, 2011). Full resolution spectra were analyzed using projection to latent structure discriminant analysis (PLS-DA) and orthogonal (O)-PLS-DA (SIMCA $P$ v.12; Umetrics AB, Umea, Sweden) to identify molecules that were present at different levels between PCP-treated and control rats. Data were modeled using MATLAB v.6.5 (The Mathworks, Natick, MA) and scripts proprietary to Imperial College (London, UK). All experiments were performed under blind and randomized conditions.

Pyruvate assays. Tissues were extracted in $4 \mu \mathrm{l}$ of buffer (BioVision Pyruvate Assay Kit; Biovision, Milpitas, CA)/mg tissue and the resulting homogenate was filtered using $3 \mathrm{kDa}$ cutoff Amicon ultraspin columns (Merck Millipore, Billerica, MA) for $30 \mathrm{~min}$ at $14000 \mathrm{~g}$. Pyruvate activity was measured according to the manufacturer's instructions.

\section{Proteomics}

Protein extraction, fractionation and digestion. Tissues were individually subjected to subcellular fractionation using either the Qproteome Cell Compartment Kit (Qiagen, West Sussex, UK), the Subcellular Proteome Extraction Kit (Merck, Nottingham, UK) (A), as described 
in Chan et al (2011) and Ma et al (2009), or using differential centrifugation combined with anion exchange chromatography (B). An experimental workflow is shown in Supplementary Figure 1.

For method B, the tissue was coarsely sectioned and homogenized through sonication (two times for $5 \mathrm{~s}$ ) in a 1:10 tissue: volume ratio of $5 \mathrm{mM}$ Tris- $\mathrm{HCl}$, containing $300 \mathrm{mM}$ sucrose, $0.1 \mathrm{mM}$ EDTA, Complete Mini proteaseand phosphatase inhibitor (Roche, Burgess Hill, UK). The homogenate was centrifuged for $15 \mathrm{~min}$ at $1000 \mathrm{~g}$ and the supernatant retained. The pellet was re-extracted with $500 \mu \mathrm{l}$ of the same buffer and supernatants pooled and clarified by brief centrifugation (soluble fraction). The pellet was suspended in $20 \mathrm{mM}$ Tris- $\mathrm{HCl}$ (containing 1\% Triton $\mathrm{X}-100$ and $0.1 \mathrm{mM}$ EDTA), and incubated for $3 \mathrm{~h}$ at $4{ }^{\circ} \mathrm{C}$ in an orbital shaker. The samples were centrifuged for $30 \mathrm{~min}$ at $13300 \mathrm{~g}$ and the resulting supernatants retained (membrane fraction). The samples were next subjected to strong anion exchange chromatography using a $4-250 \mathrm{~mm}$ ProPac SAX-10 column. (Dionex, Camberley, UK). Cytosolic fraction samples were injected in buffer A $\left(\mathrm{H}_{2} \mathrm{O}+20 \mathrm{mM}\right.$ Tris-HCl, $\mathrm{pH}$ 8.5) using the Famos autosampler (LC-Packings; Dionex, Camberley, UK). A gradient was applied as follows using the split-flow Ultimate LC (LC-Packings; Dionex): $100 \% \mathrm{~A} / 0 \% \mathrm{~B}\left(\mathrm{H}_{2} \mathrm{O}+2 \mathrm{M} \mathrm{NaCl}\right)$ for $16 \mathrm{~min}$, linear gradient to $27 \% \mathrm{~B}$ in 9 min; maintain $27 \%$ A for $15 \mathrm{~min}$, linear gradient to $48 \% \mathrm{~B}$ in $7 \mathrm{~min}$, maintain at $48 \% \mathrm{~B}$ for $15 \mathrm{~min}$; and return to initial conditions for $15 \mathrm{~min}$. A single fraction was collected after $26.5 \mathrm{~min}$ for $1 \mathrm{~min}$ using the Probot (LC-Packings; Dionex) fraction collector. The sample was precipitated using 4:1 volumes ice-cold acetone:sample and the resulting pellets were suspended in $50 \mu \mathrm{l} 50 \mathrm{mM} \mathrm{NH} \mathrm{HCO}_{3}$ (pH 8.0). The nonfractioned membrane protein fraction was suspended in $50 \mu \mathrm{l}$ of $50 \mathrm{mM} \mathrm{NH}_{4} \mathrm{HCO}_{3}(\mathrm{pH} 8.0$ ) containing $0.1 \%$ AALS1 Progenta Anionic Acid Labile Surfactant (ProteaBiosciences, Nimes, France). Sulfhydryl groups on proteins were reduced by incubation with $5 \mathrm{mM}$ DTT at $60^{\circ} \mathrm{C}$ for $30 \mathrm{~min}$ and alkylated by incubation in the dark at $37^{\circ} \mathrm{C}$ for $30 \mathrm{~min}$ with $10 \mathrm{mM}$ iodoacetamide. Proteolysis was performed using porcine trypsin (1:50, trypsin:protein; Promega, Madison, WI) for $16 \mathrm{~h}$ at $37^{\circ} \mathrm{C}$ and stopped by the addition of $8.8 \mathrm{M} \mathrm{HCl}$ to a final concentration of $0.2 \mathrm{M}$.

Liquid chromatography and mass spectrometry analysis. Samples were analyzed individually in three technical replicates using splitless nano-ultra-performance liquid

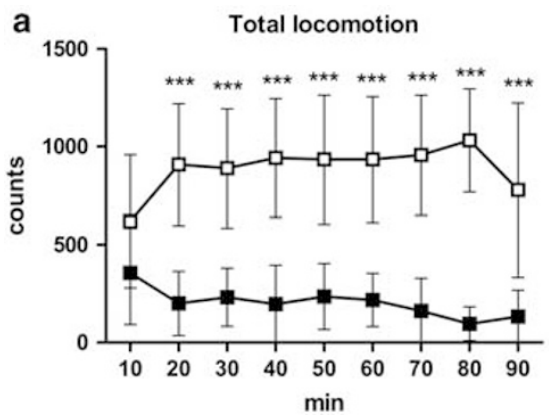

chromatography (LC) (10 kpsi nanoAcquity; Waters Corporation, Milford, MA) coupled online trough a New Objective nanoESI emitter ( $7 \mathrm{~cm}$ length, $10-\mathrm{mm}$ tip; New Objective, Woburn, MA) to a Waters Q-TOF Premier mass spectrometer and data were acquired in expression mode $\left(\mathrm{MS}^{\mathrm{E}}\right)$. The procedure, quality assessment, and data processing were performed as described previously (Ernst et al, 2012). LC$\mathrm{MS}^{\mathrm{E}}$ data were processed using the ProteinLynx Global Server (PLGS) v.2.4. (Waters Corporation) and Rosetta Elucidator v.3.3. (Rosetta Biosoftware, Seattle, WA) for time and mass/ charge alignment of mass spectrometer data as described in Krishnamurthy et al (2012). The Rattus norvegicus and the Homo sapiens complete proteome fasta sequence Integr8 database were used for the assignment of protein identities. Modifications considered were carbamidomethylation of cysteines, oxidation of methionine, and phosphorylation of tyrosine, threonine, and serine. Only peptides that were present in at least two of the three replicates, present in all of the samples of each treatment group, were considered for further analysis. Quantitative peptide measurements for each replicate were normalized against the total ion volume of all deconvoluted spectra. Replicates were averaged and ratios of protein abundance for each protein were calculated based on the sum of peptides. Only proteins identified by $\geqslant 2$ peptides were considered for further analyses. Significance of protein expression differences was determined using the non-parametric Wilcoxon's signed-rank test.

\section{Results}

\section{Effect of cPCP Administration on Rat Locomotor Activity and Stereotypic Movement}

To confirm that PCP injection induced the standard increase in locomotor activity and stereotypic movement, these parameters were measured in adult rats after the 15-day treatment period. PCP-treated rats had significantly higher locomotor activity compared with saline-treated rats over the 90 - min test period (two-way ANOVA, $P$-value $=0.0001$ ). In addition, the PCP-treated rats showed significantly higher stereotypic behavior. The peak stereotypic separation was seen within the first $30 \mathrm{~min}$ following the last PCP treatment and diminished after this time (Figure 1).

\section{Metabonomics}

PLS-DA analysis following ${ }^{1} \mathrm{H}-\mathrm{NMR}$ spectroscopy analysis revealed differences in the metabolic profiles

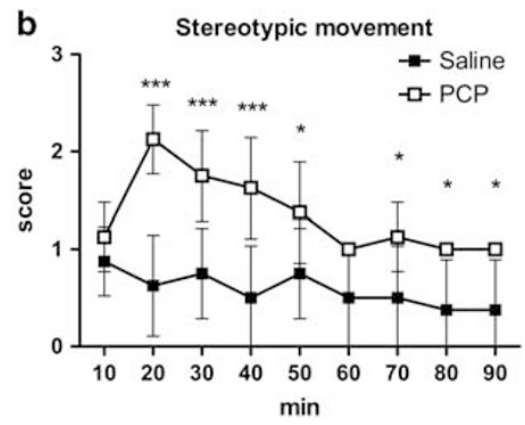

Figure I Chronic phencyclidine (PCP)-treated rats display an increase in locomotion and stereotypy similar to those seen in other pharmacological models of schizophrenia. (a) Locomotor activity and (b) stereotypy of rats treated with $5 \mathrm{mg} / \mathrm{kg}$ PCP (open squares) and saline-treated littermates (filled squares). Two-way analysis of variance (ANOVA), $p<0.000 \mathrm{I} ; n=8$ for all groups (**** $p<0.000 \mathrm{I}, * 0<0.05$ ). 

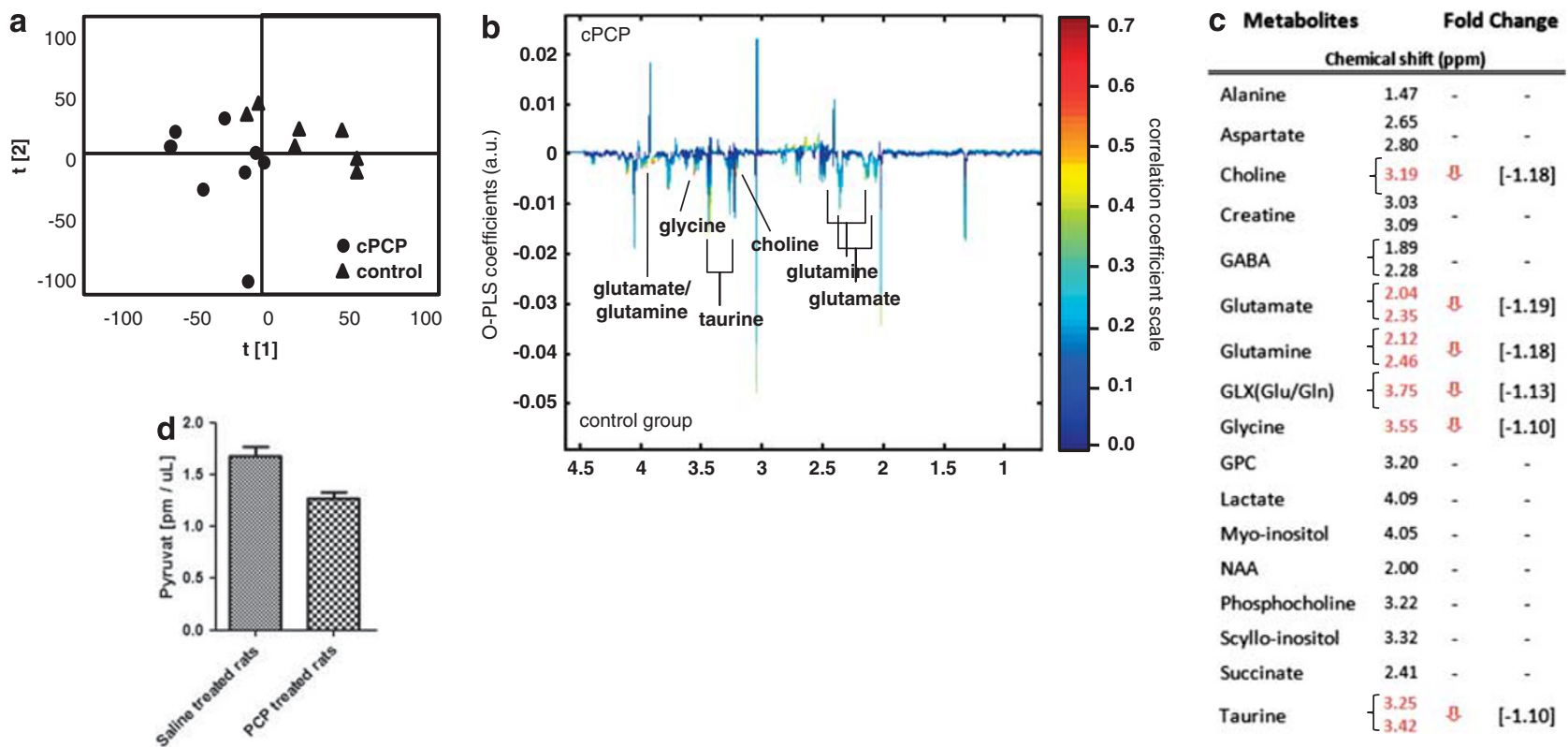

Figure 2 Multivariate and univariate analysis of full-resolution proton nuclear magnetic resonance ('H-NMR) spectral data of frontal cortices from eight phencyclidine (PCP)-treated or eight vehicle-treated rats shows metabonomic alterations in glutamate/glutamine metabolism. (a) A projection to latent structure discriminant analysis (PLS-DA) Score plot shows separation between NMR spectra from PCP- and vehicle-treated rat samples. $\left(R^{2}(X)\right.$ cum $=48 \%$, $R^{2}(Y)$ cum $=69 \%, Q^{2}=22 \%$ ). (b) Orthogonal (O)PLS-DA coefficient plot shows significantly different metabonomic profiles for PCP- and vehicle-treated rats. $\left(R^{2}(X)\right.$ cum $=30 \%, R^{2}(Y)$ cum $\left.=90 \%, Q^{2}=40 \%\right)$. Spectral regions of molecules contributing to the difference between the groups are labelled. Molecular level differences are indicated via signal orientation ( $\mathrm{up}=$ higher measurements in PCP-treated rats, down = lower measurements in PCP-treated rats). Contribution to the group difference is displayed by a correlation coefficient heat map. (c) Univariate analysis of manually integrated 'H-NMR spectral data. The table displays the fold change of analytes with a significant difference of the integrated signal. (d) Pyruvate assay showing lower pyruvate levels in frontal cortices from PCP-treated rats $(n=20)$ (Mann-Whitney test $p$-value: 0.004).

$\left(\left(Q^{2} \operatorname{cum}(0.62)\right)\right.$ in frontal cortices from PCP-treated and control rats and OPLS-DA analysis identified metabolites responsible for the differences between the treatments. This identified alterations in glutamate, glutamine, glycine, choline, and taurine levels (Figure 2). These differences were quantified and verified by manual integration of spectra (only regions showing resonances of single metabolites were considered). In addition to the ${ }^{1} \mathrm{H}-\mathrm{NMR}$ profiling analyses, we measured the levels of pyruvate using a commercial assay. This analysis identified decreased levels of pyruvate in response PCP treatment. This is consistent with the finding of decreased pyruvate kinase levels in the same frontal cortex tissue, as determined by the proteomic phase of the study.

\section{Quantitative LC-MS ${ }^{\mathrm{E}}$ Proteomic Profiling of Rat Frontal Cortex}

Subcellular fractions prepared from frontal cortices from two independent biological cohorts of PCP-treated rats were analyzed by label-free LC-MS ${ }^{\mathrm{E}}$ analysis. Because of the datadependent nature of quantitative proteomic analyses with potential shortcomings of limited sensitivity and poor reproducibility of target selection, we used two identically treated rat cohorts to demonstrate replication of the findings. Different fractionation techniques were used in an attempt to minimize technical bias and to increase the total number of proteins identified. LC-MS ${ }^{\mathrm{E}}$ analysis resulted in the identification of 843 proteins for method A, of which 32 proteins showed significant differences in abundance in the comparison of PCP- and vehicle-treated rats. Likewise, the use of method $B$ resulted in the identification a total of 1180 total proteins, and 45 of these showed significant differences in abundance between the treatment groups (Supplementary Tables 2 and 3. In an attempt to increase the validity of these findings, we used a ranking system, which selected proteins that showed significant differences in abundance $(p<0.01)$, those which were replicated in both cohorts, or in cases where multiple components of the same protein or protein complex showed parallel changes (Table 1). Changes in the PCP rat model were linked to literature of previous proteomic or transcriptomic analyses of SCZ brain tissues (Table 1). These included, $\mathrm{Ca}^{2+}$-activated proteins and sensors such as $\mathrm{Ca}^{2+}$ /calmodulin-dependent protein kinase II (CAMK2), calcineurin $\mathrm{A}$ and the visinin-like protein (VSNL1), the cytoskeletal regulator actin-related protein (ARP3) and the metabolic proteins pyruvate kinase (PKLR) and aspartate aminotransferase (GOT2). The levels of the subunits of CAMK2 (CAMK2A, CAMK2B) were correlated significantly (Supplementary Figure 2).

In addition, we used a ranked product method (Breitling et al, 2004) to identify proteins, which were altered reproducibly across the two independent sample sets. This approach selected the proteins that are altered with significance across both cohorts. Using this method, 11 significantly changing proteins were detected in the membrane fractions and 3 in the cytosolic fractions $(p<0.05)$. Specifically, increased levels of proteins involved in glutamate signaling were identified, such as the vesicular glutamate 
Table I Differentially Expressed Proteins Identified in the Frontal Cortex Of Chronic (C) PCP-Treated Rat $(p<0.05)$ and in Post-Mortem DPFLC from Schizophrenic Patients $(p<0.05)$

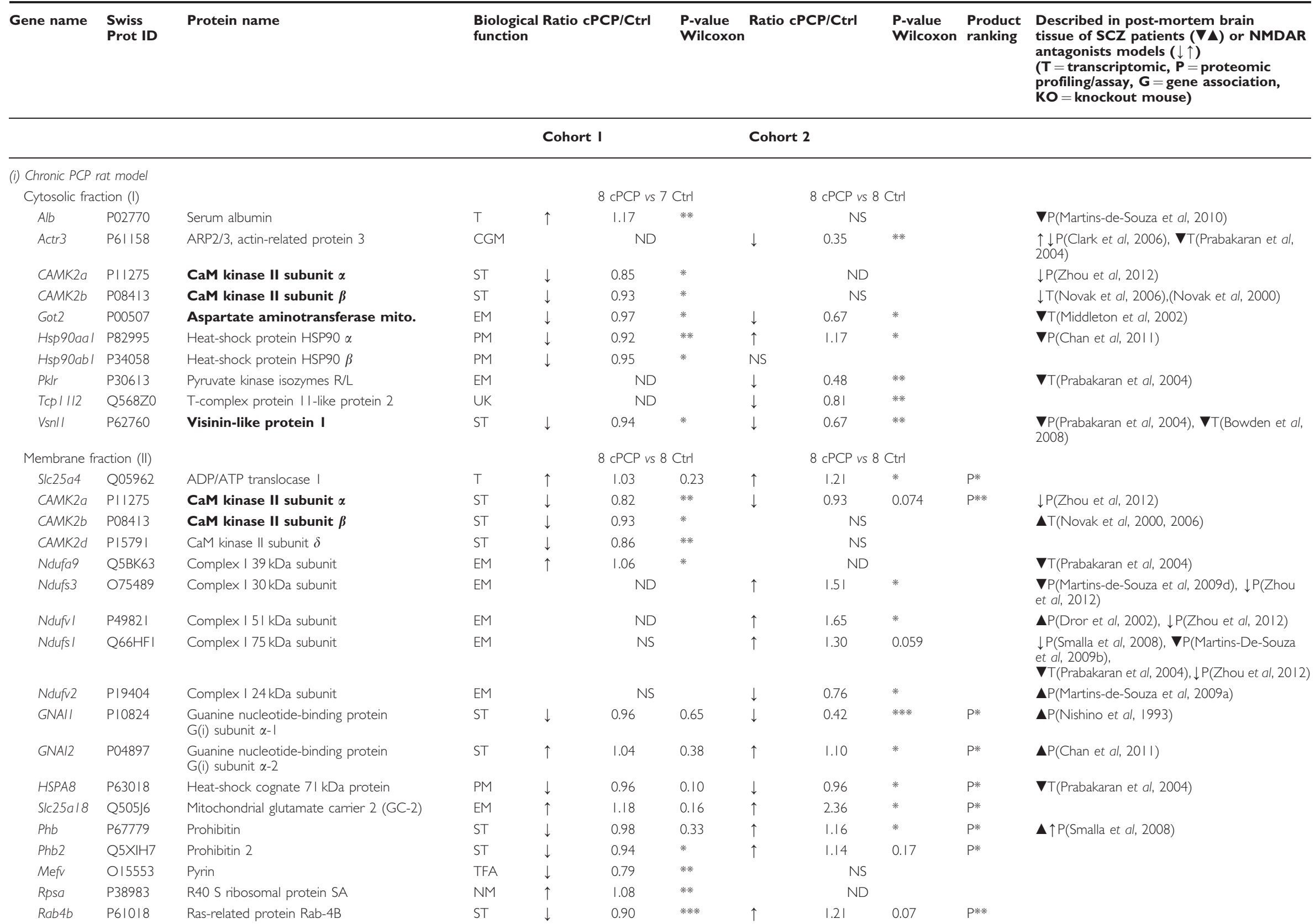


Table 1 (Continued)

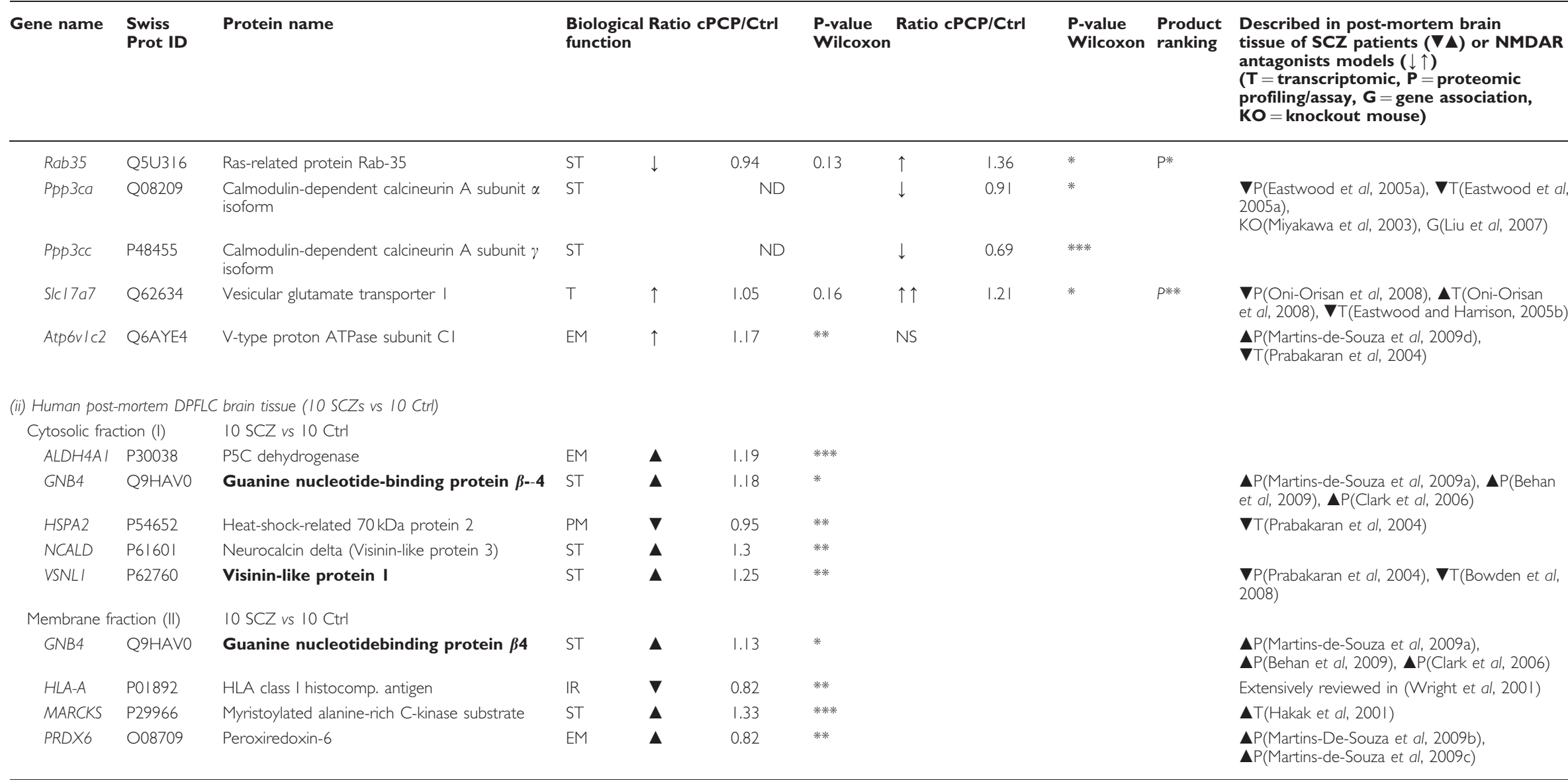

Abbreviations: ND, not detected; NS, not significantly changed; Biological function: CGM, cell growth and/or maintenance; EM, energy metabolism; IM, immune response; NM, regulation of nucleobase; nucleoside, nucleotide acid metabolism; PM, protein metabolism; ST, signal transduction; TFA, transcription factor activity; T, transport; UK, biological process unknown.

Bold represents overlapping proteins across fractions or species; $\uparrow$, increased, $\downarrow$, decreased.

*, **, and **** $\leqslant 0.05,0.01$, and 0.00I, respectively. p-Values were determined using Wilcoxon's signed-rank test and corrected to control for multiple hypothesis testing (Benjamini and Hochberg, 1995). 
transporter 1 (SLC17A7) and the mitochondrial glutamate carrier 2 (SLC25A18) (Table 1: product ranking column).

\section{Quantitative LC-MS ${ }^{\mathrm{E}}$ Proteomic Profiling of Post-Mortem DLPFC from SCZ Patients}

We used an identical label-free LC-MS $^{\mathrm{E}}$ approach as described above (via method A) for the analysis of postmortem DLPFC samples from 10 chronic SCZ patients and 10 matched controls. This resulted in the identification of 1920 proteins, of which 53 were differentially expressed (Supplementary Table 4). Table 1 lists the proteins that were altered using the same cutoff criteria as used in the analysis of the PCP-treated rats. This revealed changes in P5C dehydrogenase (ALDH4A1), heat-shock-related $70 \mathrm{kDa}$ protein 2 (HSPA3), and the two calcium-related proteins, VSNL1 and neurcocalcin-delta (NCALD), in the cytosolic fraction. Analysis of the membrane protein-enriched fraction resulted in the identification of changes in myristoylated alanine-rich C-kinase substrate (MARCKS), peroxiredoxin 6 (PRDX6), and HLA-class histocompability complex (HLAA). Increased levels of guanine nucleotidebinding protein $\beta-4$ (GNB4) were identified in both fractions.

\section{Pathway Analysis}

The accession codes for the differentially expressed proteins in brain tissues from the PCP rat model and human SCZ patients were uploaded into the Ingenuity Pathways Knowledge Base (IPKB) to identify significant interaction networks and biological pathways associated with the data. Global pathway analysis of the entire list of differentially expressed proteins showed that the most significant function associated with the altered proteins were 'polarization of neurons' in the case of the PCP rat model and 'efflux of dopamine' for the human SCZ samples (see Table 2). In addition, proteins associated with 'elongation of neurites', 'outgrowth of axons', and 'development of dendrites' were identified in the case of the rat PCP model, 'organization of cytoskeleton filaments' were found for the human SCZ samples, and changes in 'long-term potentation' was identified in both the rat and human studies. Alterations in 'glutamate metabolism' were identified in the frontal cortex tissue from both the PCP rats and SCZ patients, as shown by changes in SLC17A7 and SLC25A18. This was consistent with the results of the ${ }^{1} \mathrm{H}-\mathrm{NMR}$ profiling analysis above, which indicated changes in glutamate and glutamine. The most significant network associated with the altered proteins contained $\mathrm{Ca}^{2+}$ signaling proteins and included $\mathrm{Ca}^{2+}$ channels as hub proteins for the PCP rat and human samples.

\section{Discussion}

Currently, there is only a limited understanding of the disease mechanisms of SCZ. Animal models have proven useful for modeling certain aspects of the disease process, such as neurotransmitter alterations, but so far most studies have focused only on the associated behavioral changes in these models, which cannot easily be translated to human studies of the disease. This is the first study that has carried out an extensive molecular profiling analysis of brain tissue from the PCP rat model of schizophrenia, which has been used widely in drug development studies. The novelty of the current approach included the combined application of ${ }^{1} \mathrm{H}-\mathrm{NMR}$ profiling, allowing the investigation of small molecules in conjunction with comprehensive LC-MS ${ }^{\mathrm{E}}$ analyses of the proteomic profiles. In addition, we associated the proteomic findings with changes identified in similar analyses of the frontal cortex tissue from chronic SCZ patients in an attempt to identify potential translation points.

We first established that the PCP treatment resulted in stimulation of locomotion and stereotypical movements, the standard behavioral readouts of this model. This provided face validity for the model as used in this study. Next, molecular profiling of brain tissue of PCP rats and human SCZ showed that the main alterations involved effects on $\mathrm{Ca}^{2+}$ signaling and potential downstream effects on cytoskeletal (Mattson, 1992; Ramakers et al, 2001) and metabolic processes (Gellerich et al, 2012). $\mathrm{Ca}^{2+}$ signaling in excitatory neurons is known to be mediated by glutamate receptors and is responsible for regulating a large number of functions such as information processing and changes in synaptic plasticity that underlie learning and memory (Berridge, 1998). Remodeling of the $\mathrm{Ca}^{2+}$ signaling system, to maintain phenotypic stability, has been implicated in the etiology of SCZ, bipolar disorder, and Alzheimer's disease (Braunewell, 2005).

From the combined metabonomic, proteomic, and in silico pathway findings, we have constructed a molecular model of PCP-induced SCZ-like symptomatology summarizing our findings (Figure 3). The disturbed spatiotemporal properties of the $\mathrm{Ca}^{2}+$ influx lead to functional changes via direct and indirect downstream effector systems (eg, chromatin and cytoskeletal remodeling, protein synthesis, and gene transcription; Berridge, 1998), as found in the proteomic and metabonomic profiling of the PCP rats in this study. Such changes might explain the abnormal neural activity and cognitive, emotional, and behavioral dysfunction seen in human SCZ.

In line with this, we found parallel decreases in the levels of three $\mathrm{Ca}^{2+} /$ calmodulin-dependent protein kinase subunits (CAMK2A, CAMK2B, and CAMK2D) in the frontal cortex from the PCP-injected rats analyzed in this study. The CAMK family regulates a range of processes associated with synaptic plasticity and cognition, including long-term potentiation (Fink and Meyer, 2002; Yamauchi, 2005), and has been associated previously with SCZ (Novak et al, 2006) and PCP treatment (Mouri et al, 2007b). We also found that subunits of the multifunctional calcium-dependent serine/ threonine phosphatase calcineurin A were altered in the PCP rats. This family of proteins is also known to be involved in various aspects of synaptic plasticity (Baumgartel and Mansuy, 2012; Mulkey et al, 1994). Calcineurin A has specific roles in regulating cross-talk between glutamate and dopamine signaling, including effects on dopamine- and cAMP-regulated neuronal phosphoprotein DARP32, which serves as a branch point between dopamine receptor 1 and NMDA receptor signaling pathways (Greengard et al, 1999). Therefore, an alteration of calcineurin A is likely to have effects on both the negative and positive symptoms of SCZ as demonstrated in a 
Table 2 Top Networks and Associated Functions Involved in the Effects of PCP and in the Exploratory Study of DLPFC of Schizophrenia Patients via In Silico Pathway Analysis

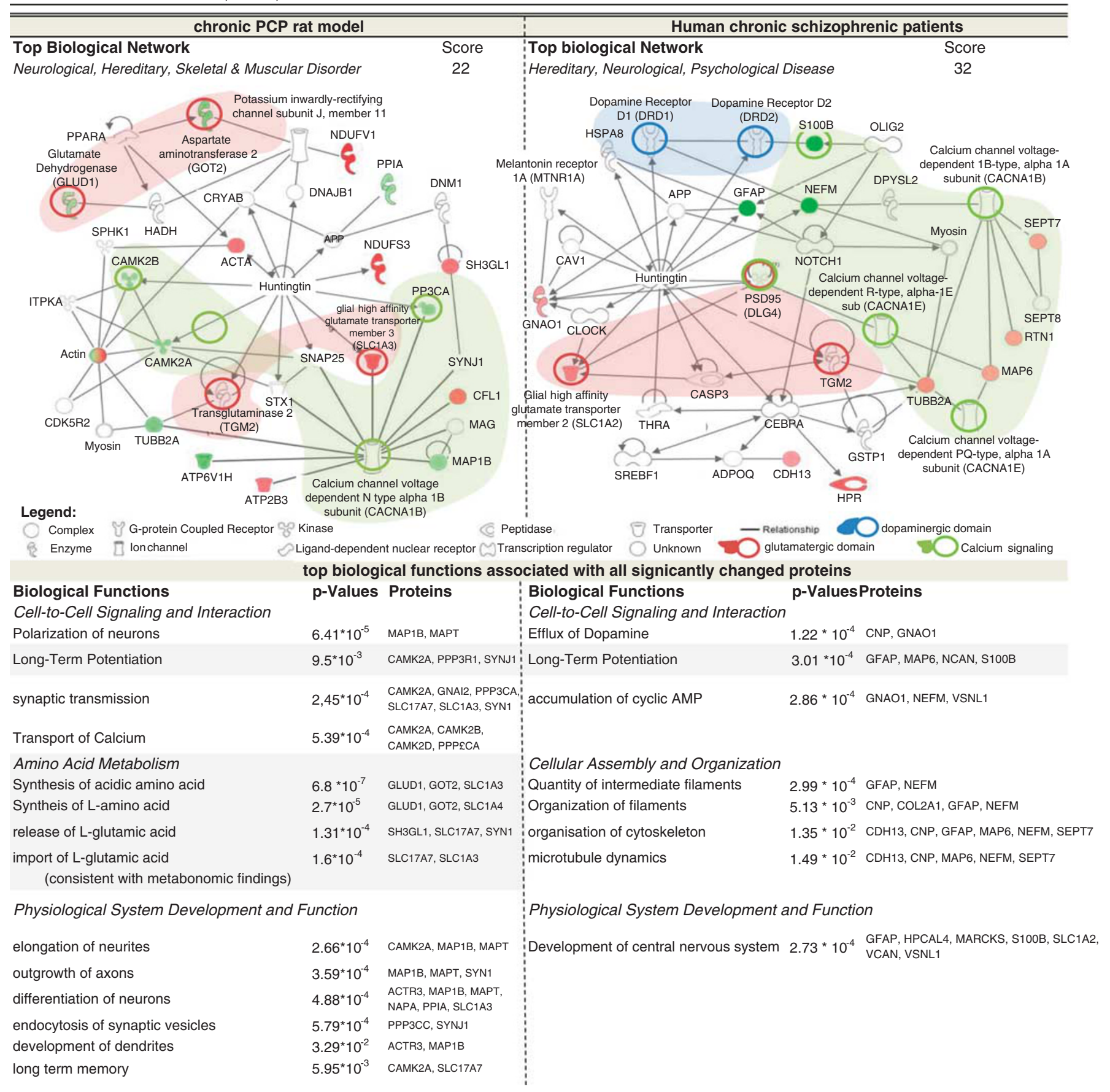

Overrepresented functions/pathways in the data set were identified by global pathway analysis using the IPKB software. All altered proteins in the model and the schizophrenic patients $(p<0.05)$ were used for network analysis based on criteria annotated in the IPKB database. The IPKB contains molecular information available in the scientific literature. Networks are generated algorithmically on the basis on the connectivity derived from molecular interaction information and scored according to the significant number of focus proteins. Furthermore biological functions were identified overlaying the significantly altered molecules onto predefined maps containing functional or pathway information of the IPKB database. Right-tailed Fisher's exact test was used to calculate $p$-values for the assigned pathways. Proteins are indicated by their gene names. Red and green symbols/text increased and decreased proteins, respectively.

previous preclinical study (Miyakawa et al, 2003). This is the first report of changes in this protein in association with a PCP rat model. Although no alteration of calcineurin A was found in our initial proteomic screen of human DLPFC from SCZ patients and controls, pathway analysis revealed alterations in both dopaminergic and glutamatergic systems, which may be linked through the phosphorylation of DARP32 by this protein. Furthermore, the catalytic subunit of calcineurin, PPP3CC, has been implicated as an SCZ susceptibility gene (Gerber et al, 2003). 


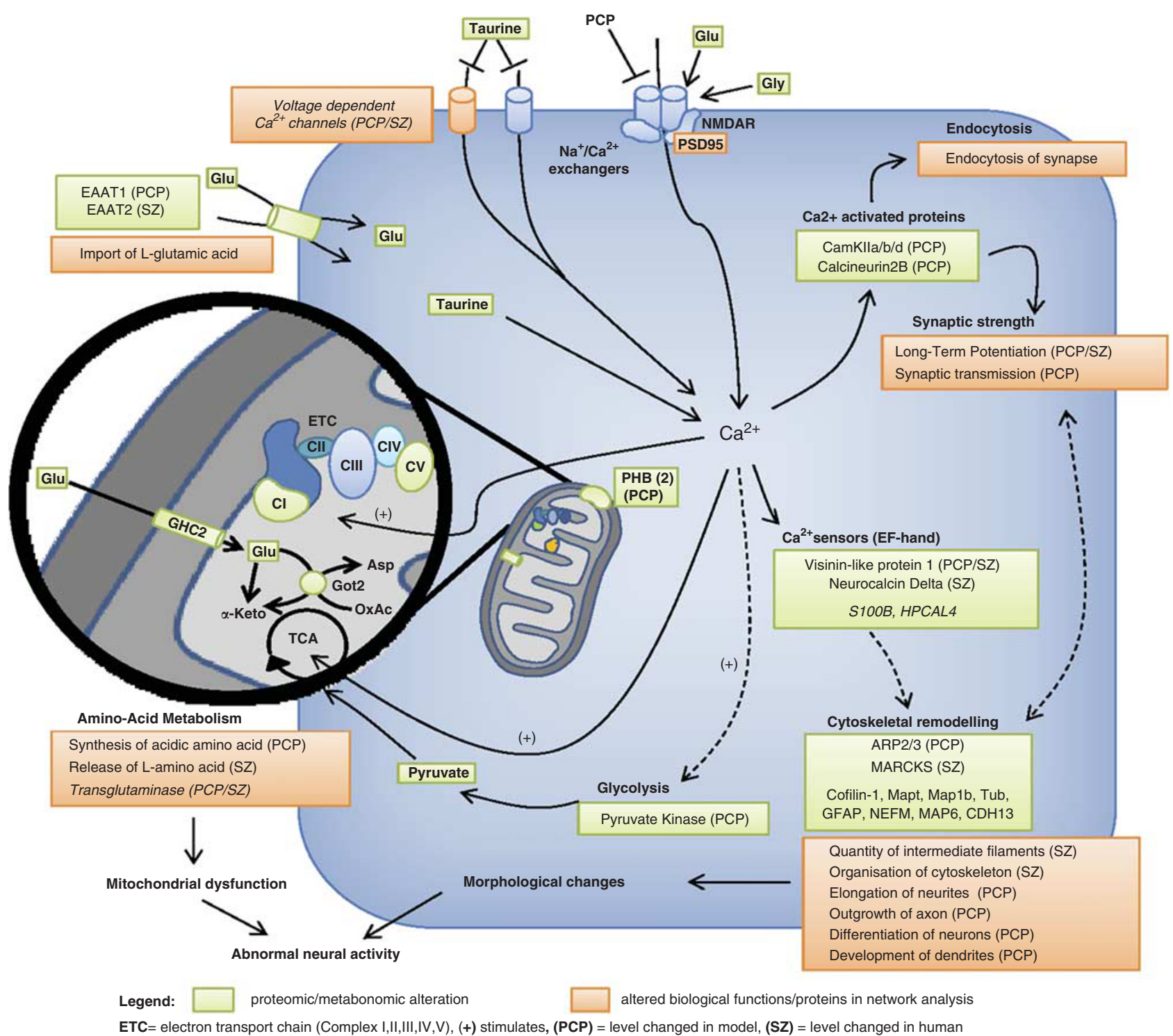

Figure 3 Model showing the proposed mechanisms underlying phencyclidine (PCP)-triggered psychosis. Green boxes: altered levels of molecules determined by proton nuclear magnetic resonance ( ${ }^{\mathrm{I}} \mathrm{H}-\mathrm{NMR}$ ) and LC-MS (liquid chromatography-mass spectrometry in expression mode) analyses Orange boxes: altered pathways determined by in silico pathway analysis using the IPKB software. Decreased $\left[\mathrm{Ca}^{2+}\right]$ levels induced by PCP treatment (blockade of N-methyl-D-aspartate (NMDA) receptors) leads to alterations of calmodulin-dependent protein kinase II (CAMK2) subunits, PPP3CC and $\mathrm{Ca}^{2+}$ sensors VSNLI and neurcocalcin-delta (NCALD). Alterations in these proteins is thought to lead to cytoskeletal remodeling (ARP2/3) and changes in long-term potentiation, synaptic transmission, and endocytosis (Berridge, 2012). The disturbed intracellular Ca ${ }^{2+}$ levels (regulated by taurine via voltagedependent $\mathrm{Ca}^{2+}$ channels and ionotropic glutamate receptors (Bulley and Shen, 20I0) affect the energy metabolism via modulating glycolytic and tricarboxylic acid (TCA) kinase activities and changes in amino-acid metabolism (Bak et al, 2006; Hajnoczky et al, 1995; Hansford, I 994; Jouaville et al, I999; McCormack et al, 1990). Morphological and energy balance changes might ultimately lead to an abnormal neural activity.

We found that only one protein, VSNL1, was changed in common in the frontal cortex of the CPCP model and post-mortem DLPFC of chronic schizophrenic patients. However, this protein was decreased in the rodents and increased in the SCZ patients. This discrepancy could be due to species differences or it may result from the fact that all patients had suffered from chronic SCZ and most had been medicated with a relatively low dose of antipsychotics over this time, which could affect $\mathrm{Ca}^{2+}$ signaling pathways. VSNL1 transduces $\mathrm{Ca}^{2+}$ signals in the brain and interacts with the membrane where it binds to receptors in a $\mathrm{Ca}^{2+}$ dependent manner (Wang et al, 2011). Single-nucleotide polymorphisms in the VSNL1 gene have been linked to SCZ in association with cognitive impairment (Braunewell et al, 2011). Alterations in expression of this protein have also been linked to the morphological and functional deficits observed in SCZ (Hong et al, 2009). Previous post-mortem studies of brain tissue from SCZ patients and analyses of a ketamine-injected rodent model have shown a reduction in the numbers and staining intensity of VSNL1-positive pyramidal neurons (Bernstein et al, 2003; Bernstein et al, 2002). These results have been confirmed by microarray and proteomic studies (Miklos and Maleszka, 2004; Vercauteren et al, 2007). Consistent with the change in 
VSNL1 levels in the PCP rats and human SCZ analyses, we also found that the visinin-like protein NCALD was altered in DLPFC from SCZ patients. NCALD, also known as VSNL3, is a high-affinity $\mathrm{Ca}^{2+}$ sensor that has been found to interact with cytoskeletal proteins (Paterlini et al, 2000).

In SCZ, evidence for brain mitochondrial dysfunction has been reported, including findings of impaired brain energy metabolism, developmental deviations, abnormal neurotransmission, and connectivity (Manji et al, 2012; Rosenfeld et al, 2011), along with mitochondrial hypoplasia, oxidative phosphorylation system imbalance, and altered mitochondrial protein expression (Karry et al, 2004; Prabakaran et al, 2004). Consistent with these reports, we detected alterations of several subunits of the electron transport chain complex I in the frontal cortex tissue from PCP-treated rats (NDUFA9, NDUFS3, NDUFV1, and NDUFV2). These alterations might be caused by regulatory effects of the $\mathrm{Ca}^{2+}$ signaling on the mitochondrial system (Cali et al, 2012). Calcium stimulates the activity of two $\mathrm{Ca}^{2+}$-sensitive tricarboxylic acid cycle (TCA) dehydrogenases, the pyruvate dehydrogenase (Hansford, 1994; McCormack et al, 1990), and enhances electron flow and ATP production through the electron transport chain (Bak et al, 2006; Hajnoczky et al, 1995; Jouaville et al, 1999). The identified mitochondrial abnormalities might lead to abnormal neuronal metabolism, function, plasticity, and brain circuitry (Albensi et al, 2000; Calabresi et al, 2001; Weeber et al, 2002), which are likely to result in the behavioral and cognitive dysfunctions observed in CPCP animal models. Providing a further link to mitochondrial dysfunction, we identified decreased levels of pyruvate kinase and we validated this finding at the functional level using pyruvate assay. Altered pyruvate levels were identified in a recent global metabolic profiling study involving 112 schizophrenic patients and 110 healthy subjects, and this was then used in a potential novel diagnostic panel for SCZ (Yang et al, 2013). In addition, converging evidence suggests that malfunction of energy supply through the brain glycolytic and TCA cycles is a causative factor of SCZ (Hazlett et al, 2004; Olsen et al, 2008). We also identified decreased levels of the anaplerotic enzyme GOT2 (also known as aspartate aminotransferase) in brains from the PCP-treated rats. This is consistent with our findings of decreased glutamine and glutamate levels, considering the role of this protein in the glutamate/ glutamine shuttle in neurons and astrocytes (Owen et al, 2002). Decreased glutamate levels have previously been described in the prefrontal cortex of SCZ patients (Tsai et al, 1995) and increased glutamine levels were found in a metabonomic profiling performed with the same sample cohort used in this study (Chan et al, 2011). A previous study showed that PCP injection resulted in a decrease of glutamate release in the frontal cortex of wild-type mice (Li et al, 2010). We also identified changes in the levels of glycine and taurine. The findings of reduced levels of glutamate and glycine replicated recent metabonomic findings in the frontal cortex tissue of similar PCP-treated rats ((Bustillo et al, 2012). Taurine is known to be involved in the reduction of glutamate-induced $\mathrm{Ca}^{2+}$ accumulation (Chen et al, 2001) and other studies have shown a reciprocal regulation of taurine and glutamate response via $\mathrm{Ca}^{2+}$ / calmodulin-dependent pathways in neurons (Bulley and Shen, 2010).
There are some limitations to this study, which suggest that further work may be required to establish the translatability of the CPCP rat model for SCZ. First, the human brain analysis was comprised of only 10 SCZ and 10 control samples, which automatically confers low statistical power for the identification of differentially expressed molecules. This problem could be compounded by the heterogeneous nature of complex disorders such as SCZ. Reflecting only a small sample set of the underlying disease population, this could lead to false negatives, and thus the pathways altered could be misrepresented. Furthermore, this could result in inconsistent changes compared with the PCP model. Another shortcoming is that the employed approaches focus on global changes of the frontal cortex metabolite and proteome composition, although the frontal cortex is a hetereogeneous structure comprised of different subpopulations of brain cells. As it is possible that only specific cell types or specific loci are affected, this could lead to a dilution of the magnitude of the changes. Therefore, further studies are warranted, which use techniques such as laser capture microscopy for profiling of more specific regions, although the availability of high-quality postmortem materials from psychiatric patients remains a limiting factor. Finally, as with most studies of animal models or post-mortem brain tissues, it is not possible to conclude whether the observed molecular changes are causative factors or the result of an adaptive response. In the case of the rat model, these changes could result from the pharmacological response to PCP injection without necessarily reflecting the changes seen in drug-naive SCZ patients. Likewise, the changes seen in the post-mortem SCZ samples could be because of the chronic disease state or even a result of other confounding factors such as different antipsychotic treatment regimens that each patient underwent in their lifetime. However, this study attempted to account for such factors by correlation analysis.

\section{Conclusions}

This study highlights the utility of subproteome and metabonome profiling approaches for the molecular characterization of translational animal models for psychiatric disorders. The results of the parallel profiling studies of the CPCP rat model and human SCZ brain tissues, as carried out here, might help to understand pathological mechanisms underlying SCZ and to identify novel functional pathways and potential new drug targets. This in turn could support innovative drug discovery and development for SCZ and other related psychiatric disorders. Both proteomic and metabonomic findings demonstrate a small degree of overlapping changes in brain tissue from the $\mathrm{PCP}$ rat model and SCZ patients. This suggests that only some aspects of the complex SCZ pathophysiology are recapitulated in the PCP rat model. It remains unclear how closely these changes are associated with the SCZ symptomatology, as many aspects of this cannot be evaluated in rodent models (eg, the presence of psychotic phenomena). We suggest that a combination of animal models and other novel cellular systems may yield more relevant information and help to represent more aspects of the human disease. 


\section{FUNDING AND DISCLOSURE}

PCG and SB are consultants for Myriad-RBM, although this does not interfere with journal policies regarding sharing of data or materials. The other authors declare that no financial support or compensation has been received from any individual or corporate entity for research or professional service and there are no personal financial holdings that could be perceived as constituting a potential conflict of interest.

\section{ACKNOWLEDGEMENTS}

This research was kindly supported by the Stanley Medical Research Institute (SMRI), the Innovative Medicines Initiative for Novel Methods leading to New Medications in Depression and Schizophrenia (IMI NEWMEDS), and the Dutch Fund for Economic Structure Reinforcement ((No. 0908) the NeuroBasic PharmaPhenomics project).

\section{REFERENCES}

Albensi BC, Sullivan PG, Thompson MB, Scheff SW, Mattson MP (2000). Cyclosporin ameliorates traumatic brain-injury-induced alterations of hippocampal synaptic plasticity. Exp Neurol 162: 385-389.

Bak LK, Schousboe A, Sonnewald U, Waagepetersen HS (2006). Glucose is necessary to maintain neurotransmitter homeostasis during synaptic activity in cultured glutamatergic neurons. J Cerebr Blood Flow Met 26: 1285-1297.

Baumgartel K, Mansuy IM (2012). Neural functions of calcineurin in synaptic plasticity and memory. Learn Mem 19: 375-384.

Behan AT, Byrne C, Dunn MJ, Cagney G, Cotter DR (2009). Proteomic analysis of membrane microdomain-associated proteins in the dorsolateral prefrontal cortex in schizophrenia and bipolar disorder reveals alterations in LAMP, STXBP1 and BASP1 protein expression. Mol Psychiatry 14: 601-613.

Benjamini Y, Hochberg Y (1995). Controlling the false discovery rate-a practical and powerful approach to multiple testing. $J$ R Stat Soc Ser B 57: 289-300.

Bernstein HG, Becker A, Keilhoff G, Spilker C, Gorczyca WA, Braunewell KH et al (2003). Brain region-specific changes in the expression of calcium sensor proteins after repeated applications of ketamine to rats. Neurosci Lett 339: 95-98.

Bernstein HG, Braunewell KH, Spilker C, Danos P, Baumann B, Funke $S$ et al (2002). Hippocampal expression of the calcium sensor protein visinin-like protein-1 in schizophrenia. NeuroReport 13: 393-396.

Berridge MJ (1998). Neuronal calcium signaling. Neuron 21: 13-26.

Berridge MJ (2012). Calcium signalling remodelling and disease. Biochem Soc Trans 40: 297-309.

Bowden NA, Scott RJ, Tooney PA (2008). Altered gene expression in the superior temporal gyrus in schizophrenia. BMC Genom 9: 199.

Braunewell KH (2005). The darker side of $\mathrm{Ca}^{2+}$ signaling by neuronal $\mathrm{Ca}^{2+}$-sensor proteins: from Alzheimer's disease to cancer. Trends Pharmacol Sci 26: 345-351.

Braunewell KH, Dwary AD, Richter F, Trappe K, Zhao C, Giegling I et al (2011). Association of VSNL1 with schizophrenia, frontal cortical function, and biological significance for its gene product as a modulator of cAMP levels and neuronal morphology. Transl Psychiatry 1: e22.

Breitling R, Armengaud P, Amtmann A, Herzyk P (2004). Rank products: a simple, yet powerful, new method to detect differentially regulated genes in replicated microarray experiments. FEBS Lett 573: 83-92.
Bulley S, Shen W (2010). Reciprocal regulation between taurine and glutamate response via $\mathrm{Ca}^{2+}$ - dependent pathways in retinal third-order neurons. J Biomed Sci 17: S5.

Bustillo J, Galloway MP, Ghoddoussi F, Bolognani F, PerroneBizzozero N (2012). Medial-frontal cortex hypometabolism in chronic phencyclidine exposed rats assessed by high resolution magic angle spin $11.7 \mathrm{~T}$ proton magnetic resonance spectroscopy. Neurochem Int 61: 128-131.

Calabresi P, Gubellini P, Picconi B, Centonze D, Pisani A, Bonsi P et al (2001). Inhibition of mitochondrial complex II induces a long-term potentiation of NMDA-mediated synaptic excitation in the striatum requiring endogenous dopamine. J Neurosci 21: 5110-5120.

Cali T, Ottolini D, Brini M (2012). Mitochondrial $\mathrm{Ca}(2+)$ as a key regulator of mitochondrial activities. Adv Exp Med Biol 942: 53-73.

Chan MK, Tsang TM, Harris LW, Guest PC, Holmes E, Bahn S (2011). Evidence for disease and antipsychotic medication effects in post-mortem brain from schizophrenia patients. Mol psychiatry 16: 1189-1202.

Chen WQ, Jin H, Nguyen M, Carr J, Lee YJ, Hsu CC et al (2001). Role of taurine in regulation of intracellular calcium level and neuroprotective function in cultured neurons. J Neurosci Res 66: 612-619.

Clark D, Dedova I, Cordwell S, Matsumoto I (2006). A proteome analysis of the anterior cingulate cortex gray matter in schizophrenia. Mol psychiatry 11 5: 423.

Dror N, Klein E, Karry R, Sheinkman A, Kirsh Z, Mazor M et al (2002). State-dependent alterations in mitochondrial complex I activity in platelets: a potential peripheral marker for schizophrenia. Mol Psychiatry 7: 995-1001.

Eastwood SL, Burnet PWJ, Harrison PJ (2005a). Decreased hippocampal expression of the susceptibility gene PPP3CC and other calcineurin subunits in schizophrenia. Biol Psychiatry 57: 702-710.

Eastwood SL, Harrison PJ (2005b). Decreased expression of vesicular glutamate transporter 1 and complexin II mRNAs in schizophrenia: further evidence for a synaptic pathology affecting glutamate neurons. Schizophr Res 73: 159-172.

Ellison G, Switzer RC III (1993). Dissimilar patterns of degeneration in brain following four different addictive stimulants. NeuroReport 5: 17-20.

Ernst A, Ma D, Garcia-Perez I, Tsang TM, Kluge W, Schwarz E et al (2012). Molecular validation of the acute phencyclidine rat model for schizophrenia: identification of translational changes in energy metabolism and neurotransmission. J Proteome Res 11: 3704-3714.

Fink CC, Meyer T (2002). Molecular mechanisms of CaMKII activation in neuronal plasticity. Curr Opin Neurobiol 12: 293-299.

Gellerich FN, Gizatullina Z, Trumbekaite S, Korzeniewski B, Gaynutdinov T, Seppet E et al (2012). Cytosolic $\mathrm{Ca}^{2+}$ regulates the energization of isolated brain mitochondria by formation of pyruvate through the malate-aspartate shuttle. Biochem $J$ 443: 747-755.

Gerber DJ, Hall D, Miyakawa T, Demars S, Gogos JA, Karayiorgou M et al (2003). Evidence for association of schizophrenia with genetic variation in the 8 p21.3 gene, PPP3CC, encoding the calcineurin gamma subunit. Proc Natl Acad Sci USAm 100: 8993-8998.

Greengard P, Allen PB, Nairn AC (1999). Beyond the dopamine receptor: the DARPP-32/protein phosphatase-1 cascade. Neuron 23: 435-447.

Hajnoczky G, Robbgaspers LD, Seitz MB, Thomas AP (1995). Decoding of cytosolic calcium oscillations in the mitochondria. Cell 82: 415-424.

Hajszan T, Leranth C, Roth RH (2006). Subchronic phencyclidine treatment decreases the number of dendritic spine synapses in the rat prefrontal cortex. Biol Psychiatry 60: 639-644. 
Hakak Y, Walker JR, Li C, Wong WH, Davis KL, Buxbaum JD et al (2001). Genome-wide expression analysis reveals dysregulation of myelination-related genes in chronic schizophrenia. Proc Natl Acad Sci USA 98: 4746-4751.

Hansford RG (1994). Physiological role of mitochondrial $\mathrm{Ca}^{2+}$ transport. J Bioenerget Biomembr 26: 495-508.

Hashimoto K, Fujita Y, Shimizu E, Iyo M (2005). Phencyclidineinduced cognitive deficits in mice are improved by subsequent subchronic administration of clozapine, but not haloperidol. Eur J Pharmacol 519: 114-117.

Hazlett EA, Buchsbaum MS, Kemether E, Bloom R, Platholi J, Brickman AM et al (2004). Abnormal glucose metabolism in the mediodorsal nucleus of the thalamus in schizophrenia. Am J psychiatry 161: 305-314.

Hong KS, Won HH, Cho EY, Jeun HO, Cho SS, Lee YS et al (2009). Genome-widely significant evidence of linkage of schizophrenia to chromosomes 2p24.3 and 6q27 in an SNP-based analysis of Korean families. Am J Med Genet B 150B: 647-652.

Jouaville LS, Pinton P, Bastianutto C, Rutter GA, Rizzuto R (1999). Regulation of mitochondrial ATP synthesis by calcium: evidence for a long-term metabolic priming. Proc Natl Acad Sci USA 96: 13807-13812.

Karry R, Klein E, Ben Shachar D (2004). Mitochondrial complex I subunits expression is altered in schizophrenia: a postmortem study. Biol psychiatry 55: 676-684.

Keshavan MS, Tandon R, Boutros NN, Nasrallah HA (2008). Schizophrenia, 'just the facts': what we know in 2008 Part 3: neurobiology. Schizophr Res 106: 89-107.

Krishnamurthy D, Harris LW, Levin Y, Koutroukides TA, Rahmoune H, Pietsch S et al (2012). Metabolic, hormonal and stress-related molecular changes in post-mortem pituitary glands from schizophrenia subjects. World J Biol Psychiatry (epub ahead of print 17 January 2012) PMID:22248022.

Lahti AC, Koffel B, LaPorte D, Tamminga CA (1995). Subanesthetic doses of ketamine stimulate psychosis in schizophrenia. Neuropsychopharmacology 13: 9-19.

Lan MJ, McLoughlin GA, Griffin JL, Tsang TM, Huang JT, Yuan P et al (2009). Metabonomic analysis identifies molecular changes associated with the pathophysiology and drug treatment of bipolar disorder. Mol sPychiatry 14: 269-279.

Li Z, Boules M, Williams K, Peris J, Richelson E (2010). The novel neurotensin analog NT69L blocks phencyclidine (PCP)-induced increases in locomotor activity and PCP-induced increases in monoamine and amino acids levels in the medial prefrontal cortex. Brain Res 1311: 28-36.

Liu YL, Fann CS, Liu CM, Chang CC, Yang WC, Hung SI et al (2007). More evidence supports the association of PPP3CC with schizophrenia. Mol Psychiatry 12: 966-974.

Ma D, Chan MK, Lockstone HE, Pietsch SR, Jones DN, Cilia J et al (2009). Antipsychotic treatment alters protein expression associated with presynaptic function and nervous system development in rat frontal cortex. J Proteome Res 8: 3284-3297.

Manji H, Kato T, Di Prospero NA, Ness S, Beal MF, Krams M et al (2012). Impaired mitochondrial function in psychiatric disorders. Nat Rev Neurosci 13: 293-307.

Marquis JP, Goulet S, Dore FY (2003). Schizophrenialike syndrome inducing agent phencyclidine failed to impair memory for temporal order in rats. Neurobiol Learn Mem 80: $158-167$.

Martins-de-Souza D, Gattaz WF, Schmitt A, Maccarrone G, Hunyadi-Gulyas E, Eberlin MN et al (2009a). Proteomic analysis of dorsolateral prefrontal cortex indicates the involvement of cytoskeleton, oligodendrocyte, energy metabolism and new potential markers in schizophrenia. J Psychiatric Res 43: 978-986.

Martins-De-Souza D, Gattaz WF, Schmitt A, Novello JC, Marangoni S, Turck CW et al (2009b). Proteome analysis of schizophrenia patients Wernicke's area reveals an energy metabolism dysregulation. BMC Psychiatry 9: 17.
Martins-de-Souza D, Gattaz WF, Schmitt A, Rewerts C, Maccarrone G, Dias-Neto E et al (2009c). Prefrontal cortex shotgun proteome analysis reveals altered calcium homeostasis and immune system imbalance in schizophrenia. Eur Arch Psychiatry Clin Neurosci 259: 151-163.

Martins-de-Souza D, Gattaz WF, Schmitt A, Rewerts C, Marangoni S, Novello JC et al (2009d). Alterations in oligodendrocyte proteins, calcium homeostasis and new potential markers in schizophrenia anterior temporal lobe are revealed by shotgun proteome analysis. J Neural Transm 116: 275-289.

Martins-de-Souza D, Maccarrone G, Wobrock T, Zerr I, Gormanns P, Reckow S et al (2010). Proteome analysis of the thalamus and cerebrospinal fluid reveals glycolysis dysfunction and potential biomarkers candidates for schizophrenia. J Psychiatric Res 44: $1176-1189$.

Mattson MP (1992). Calcium as sculptor and destroyer of neural circuitry. Exp Gerontol 27: 29-49.

McCormack JG, Halestrap AP, Denton RM (1990). Role of calcium ions in regulation of mammalian intramitochondrial metabolism. Physiol Rev 70: 391-425.

Middleton FA, Mirnics K, Pierri JN, Lewis DA, Levitt P (2002). Gene expression profiling reveals alterations of specific metabolic pathways in schizophrenia. $J$ Neurosci 22: 2718-2729.

Miklos GL, Maleszka R (2004). Microarray reality checks in the context of a complex disease. Nat Biotechnol 22: 615-621.

Miyakawa T, Leiter LM, Gerber DJ, Gainetdinov RR, Sotnikova TD, Zeng $\mathrm{H}$ et al (2003). Conditional calcineurin knockout mice exhibit multiple abnormal behaviors related to schizophrenia. Proc Natl Acad Sci USA 100: 8987-8992.

Mouri A, Noda Y, Enomoto T, Nabeshima T (2007a). Phencyclidine animal models of schizophrenia: approaches from abnormality of glutamatergic neurotransmission and neurodevelopment. Neurochem Int 51: 173-184.

Mouri A, Noda Y, Noda A, Nakamura T, Tokura T, Yura Y et al (2007b). Involvement of a dysfunctional dopamine-D $1 / N$ methyl-D-aspartate-NR1 and Ca2 + /calmodulin-dependent protein kinase II pathway in the impairment of latent learning in a model of schizophrenia induced by phencyclidine. Mol Pharmacol 71: 1598-1609.

Mulkey RM, Endo S, Shenolikar S, Malenka RC (1994). Involvement of a calcineurin/inhibitor-1 phosphatase cascade in hippocampal long-term depression. Nature 369: 486-488.

Murai R, Noda Y, Matsui K, Kamei H, Mouri A, Matsuba K et al (2007). Hypofunctional glutamatergic neurotransmission in the prefrontal cortex is involved in the emotional deficit induced by repeated treatment with phencyclidine in mice: implications for abnormalities of glutamate release and NMDA-CaMKII signaling. Behav Brain Res 180: 152-160.

Neill JC, Barnes S, Cook S, Grayson B, Idris NF, McLean SL et al (2010). Animal models of cognitive dysfunction and negative symptoms of schizophrenia: focus on NMDA receptor antagonism. Pharmacol Ther 128: 419-432.

Nishino N, Kitamura N, Hashimoto T, Kajimoto Y, Shirai Y, Murakami $\mathrm{N}$ et al (1993). Increase in $\left[{ }^{3} \mathrm{H}\right]$ cAMP binding sites and decrease in Gi alpha and Go alpha immunoreactivities in left temporal cortices from patients with schizophrenia. Brain Res 615: 41-49.

Novak G, Seeman P, Tallerico T (2000). Schizophrenia: elevated mRNA for calcium-calmodulin-dependent protein kinase IIbeta in frontal cortex. Brain Res Mol Brain Res 82: 95-100.

Novak G, Seeman P, Tallerico T (2006). Increased expression of calcium/calmodulin-dependent protein kinase IIbeta in frontal cortex in schizophrenia and depression. Synapse 59: 61-68.

Olsen L, Hansen T, Jakobsen KD, Djurovic S, Melle I, Agartz I et al (2008). The estrogen hypothesis of schizophrenia implicates glucose metabolism: association study in three independent samples. BMC Med Genet 9: 39. 
Oni-Orisan A, Kristiansen LV, Haroutunian V, Meador-Woodruff JH, McCullumsmith RE (2008). Altered vesicular glutamate transporter expression in the anterior cingulate cortex in schizophrenia. Biol Psychiatry 63: 766-775.

Owen OE, Kalhan SC, Hanson RW (2002). The key role of anaplerosis and cataplerosis for citric acid cycle function. J Biol Chem 277: 30409-30412.

Paterlini M, Revilla V, Grant AL, Wisden W (2000). Expression of the neuronal calcium sensor protein family in the rat brain. Neuroscience 99: 205-216.

Prabakaran S, Swatton JE, Ryan MM, Huffaker SJ, Huang JTJ, Griffin JL et al (2004). Mitochondrial dysfunction in schizophrenia: evidence for compromised brain metabolism and oxidative stress. Mol Psychiatry 9: 684-697.

Qiao H, Noda Y, Kamei H, Nagai T, Furukawa H, Miura H et al (2001). Clozapine, but not haloperidol, reverses social behavior deficit in mice during withdrawal from chronic phencyclidine treatment. NeuroReport 12: 11-15.

Ramakers GJ, Avci B, van Hulten P, van Ooyen A, van Pelt J, Pool CW et al (2001). The role of calcium signaling in early axonal and dendritic morphogenesis of rat cerebral cortex neurons under non-stimulated growth conditions. Brain Res Dev Brain Res 126: 163-172.

Rosenfeld M, Brenner-Lavie H, Gal-Ben Ari S, Kavushansky A, Ben-Shachar D (2011). Perturbation in mitochondrial network dynamics and in complex I dependent cellular respiration in schizophrenia. Biological psychiatry 69: 980-988.

Sarnyai Z, Alsaif M, Bahn S, Ernst A, Guest PC, Hradetzky E et al (2011). Behavioral and molecular biomarkers in translational animal models for neuropsychiatric disorders. Int Rev Neurobiol 101: 203-238.

Smalla KH, Mikhaylova M, Sahin J, Bernstein HG, Bogerts B, Schmitt A et al (2008). A comparison of the synaptic proteome in human chronic schizophrenia and rat ketamine psychosis suggest that prohibitin is involved in the synaptic pathology of schizophrenia. Mol Psychiatry 13: 878-896.

Sturgeon RD, Fessler RG, Meltzer HY (1979). Behavioral rating scales for assessing phencyclidine-induced locomotor activity, stereotyped behavior and ataxia in rats. Eur J Pharmacol 59: 169-179.

Tsai G, Passani LA, Slusher BS, Carter R, Baer L, Kleinman JE et al (1995). Abnormal excitatory neurotransmitter metabolism in schizophrenic brains. Arch Gen Psychiatry 52: 829-836.

Vercauteren FG, Flores G, Ma W, Chabot JG, Geenen L, Clerens S et al (2007). An organelle proteomic method to study neurotransmission-related proteins, applied to a neurodevelopmental model of schizophrenia. Proteomics 7: 3569-3579.

Wang CK, Simon A, Jessen CM, Oliveira CL, Mack L, Braunewell $\mathrm{KH}$ et al (2011). Divalent cations and redox conditions regulate the molecular structure and function of visinin-like protein-1. PLoS One 6: e26793.

Weeber EJ, Levy M, Sampson MJ, Anflous K, Armstrong DL, Brown SE et al (2002). The role of mitochondrial porins and the permeability transition pore in learning and synaptic plasticity. J Biol Chem 277: 18891-18897.

Wright P, Nimgaonkar VL, Donaldson PT, Murray RM (2001). Schizophrenia and HLA: a review. Schizophr Res 47: 1-12.

Yamauchi T (2005). Neuronal $\mathrm{Ca}^{2+} /$ calmodulin-dependent protein kinase II-discovery, progress in a quarter of a century, and perspective: implication for learning and memory. Biol Pharm Bull 28: 1342-1354.

Yang J, Chen T, Sun L, Zhao Z, Qi X, Zhou K et al (2013). Potential metabolite markers of schizophrenia. Mol psychiatry 18: 67-78.

Zhou K, Yang Y, Gao L, He G, Li W, Tang K et al (2012). NMDA receptor hypofunction induces dysfunctions of energy metabolism and semaphorin signaling in rats: a synaptic proteome study. Schizophr Bull 38: 579-591.

Supplementary Information accompanies the paper on the Neuropsychopharmacology website (http://www.nature.com/npp) 